\title{
A New Nuclear Function of the Entamoeba histolytica Glycolytic Enzyme Enolase: The Metabolic Regulation of Cytosine-5 Methyltransferase 2 (Dnmt2) Activity
}

\author{
Ayala Tovy' ${ }^{1}$, Rama Siman Tov ${ }^{1}$, Ricarda Gaentzsch ${ }^{2}$, Mark Helm ${ }^{2,3}$, Serge Ankri ${ }^{1 *}$ \\ 1 Department of Molecular Microbiology, The Bruce Rappaport Faculty of Medicine, Technion, Haifa, Israel, 2 Department of Chemistry, The Pharmacy and Molecular \\ Biotechnology Institute, Ruprecht-Karls University of Heidelberg, Heidelberg, Germany, 3 The Pharmacy and Biochemistry Institute, Johannes Gutenberg University, Mainz, \\ Germany
}

\begin{abstract}
Cytosine-5 methyltransferases of the Dnmt2 family function as DNA and tRNA methyltransferases. Insight into the role and biological significance of Dnmt2 is greatly hampered by a lack of knowledge about its protein interactions. In this report, we address the subject of protein interaction by identifying enolase through a yeast two-hybrid screen as a Dnmt2-binding protein. Enolase, which is known to catalyze the conversion of 2-phosphoglycerate (2-PG) to phosphoenolpyruvate (PEP), was shown to have both a cytoplasmatic and a nuclear localization in the parasite Entamoeba histolytica. We discovered that enolase acts as a Dnmt2 inhibitor. This unexpected inhibitory activity was antagonized by 2-PG, which suggests that glucose metabolism controls the non-glycolytic function of enolase. Interestingly, glucose starvation drives enolase to accumulate within the nucleus, which in turn leads to the formation of additional enolase-E.histolytica DNMT2 homolog (Ehmeth) complex, and to a significant reduction of the tRNA ${ }^{\text {Asp }}$ methylation in the parasite. The crucial role of enolase as a Dnmt2 inhibitor was also demonstrated in E.histolytica expressing a nuclear localization signal (NLS)-fused-enolase. These results establish enolase as the first Dnmt2 interacting protein, and highlight an unexpected role of a glycolytic enzyme in the modulation of Dnmt2 activity.
\end{abstract}

Citation: Tovy A, Siman Tov R, Gaentzsch R, Helm M, Ankri S (2010) A New Nuclear Function of the Entamoeba histolytica Glycolytic Enzyme Enolase: The Metabolic Regulation of Cytosine-5 Methyltransferase 2 (Dnmt2) Activity. PLoS Pathog 6(2): e1000775. doi:10.1371/journal.ppat.1000775

Editor: William A. Petri, Jr., University of Virginia Health System, United States of America

Received September 2, 2009; Accepted January 18, 2010; Published February 19, 2010

Copyright: (c) 2010 Ankri et al. This is an open-access article distributed under the terms of the Creative Commons Attribution License, which permits unrestricted use, distribution, and reproduction in any medium, provided the original author and source are credited.

Funding: This study was supported by grants from the Israel Science Foundation and the Rappaport Family Institute for Research in the Medical Sciences, and the Deutsche Forschungsgemeinschaft (DFG). The funders had no role in study design, data collection and analysis, decision to publish, or preparation of the manuscript

Competing Interests: The authors have declared that no competing interests exist.

*E-mail: sankri@tx.technion.ac.il

\section{Introduction}

The synthesis of 5-methylcytosine in both DNA and RNA is catalyzed by methyl 5-cytosine methyltransferases (m5C-MTase) with $S$-adenosylmethionine as a cofactor. The mammalian DNA methylation machinery consists of three active DNA m5CMTases: Dnmt1, Dnmt3a and Dnmt3b. Dnmtl has a high preference for hemi-methylated DNA as a substrate [1], whereas Dnmt3a and Dnmt3b are de novo DNA MTases that act on nonmethylated DNA (for review, see Jeltsch [2]). A fourth DNA m5CMTases, Dnmt2, belongs to a large family of proteins that are conserved in all species from Schizosaccharomyces pombe to humans. Dnmt2 stands apart from the three active DNA MTases because its length is relatively short when compared to that of Dnmt3a, Dnmt3b, or Dnmt1. Furthermore, this enzyme resembles prokaryotic DNA MTases because it does not have a large $\mathrm{N}$ terminal regulatory domain [3].

Native tRNA ${ }^{\text {Asp }}$ extracted from Dnmt2-deficient mice, Arabidopsis thaliana or Drosophila melanogaster were methylated in vitro by the human Dnmt2 (hDnmt2) protein. Accordingly, it was proposed that hDnmt2 is a tRNA ${ }^{\text {Asp }}$ MTase rather than a DNA MTase [4], an idea that was further supported by the fact that it can also methylate transcribed tRNAs in vitro $[5,6]$. On the other hand, the role of Dnmt2 seems to be not essential in higher eukaryotes because loss of function mutations of the Dnmt2 gene do not change genomic methylation patterns in the mouse [7]. In addition, depletion of $D$. melanogaster Dnmt2 (dDnmt2) by RNA interference has no detectable consequences on embryonic development [8]. However, a recent report has shown that loss of Dnmt2 in somatic cells eliminates H4K20 trimethylation at retrotransposons, and impairs maintenance of retrotransposon silencing [9]. Dnmt2 has been established as a genuine DNA methyltransferase in lower eukaryotes. Dnmt2 catalyzes DNA methylation in Dictyostelium discoideum [10,11] and Entamoeba histolytica [12]. However, the weak DNA methyltransferase activity and the low expression level of Dnmt2 enzymes may explain the low methylation level that is found in these organisms [13]. Dnmt2 catalyzes cytosine methylation with a low preference for $\mathrm{Cp}(\mathrm{A} / \mathrm{T})$ [8,12,14] or $\mathrm{CG}(\mathrm{A} / \mathrm{T}) \mathrm{GG}$ [15], rather than the $\mathrm{CpG}$ motif. These results suggest that a dual specificity for DNA and RNA substrates emerged during the evolution of the Dnmt2 family [13]. Despite this dual specificity for DNA and RNA, the function of Dnmt2 as an RNA methyltransferase in lower eukaryotes has not yet been established.

The finding of interacting partners to members of the DNA/ tRNA methyltransferase Dnmt2 is crucial for improving our existing understanding of its function. Until now, no interacting candidate has been reported for this family of proteins. In contrast, numerous proteins have been shown to interact with Dnmtl and 


\section{Author Summary}

Epigenetics refers to heritable changes in gene function that occur without alterations in the DNA sequence. The best characterized epigenetic modification is DNA methylation. In mammals, DNA methylation is associated with gene silencing and transposon control. We have previously established the presence of methyl cytosine in the genome of Entamoeba histolytica, an important unicellular human pathogen. Ehmeth, an enzyme that belongs to the DNA methyltransferase 2 (Dnmt2) family, catalyzes DNA methylation in the parasite. Recent evidence in support of the notion that human Dnmt2 is a tRNA ${ }^{\text {Asp }}$ methyltransferase fuels the debate about the real function of the Dnmt2 family. Our results show that Ehmeth also catalyzes tRNA $^{\text {Asp }}$ methylation and indicates a dual function for this protein. In this study, we have also identified that enolase, a glycolytic enzyme, interacts with Ehmeth, and modulates its activity under conditions of glucose starvation. These data add to the emerging evidence that glycolytic enzymes have multifunctional roles, and emphasize the importance of energetic metabolism in the control of the epigenetic enzymatic machinery.

Dnmt3 thereby linking methylation to histone modifications and transcription regulation. For example both Dnmts were found to be associated with histone deacetylase [16,17]. Dnmtl was also found to interact with several chromatin- associated proteins, such as retinoblastoma protein, DNA methyltransferase 1 associated protein 1 and methyl CpG binding protein 2 [1], and Dnmt3 binds various transcription regulators, such as the transcriptional regulator RP58, the fusion protein of promyelocytic leukemia (PML) and the retinoic acid receptor- $\alpha($ RAR $\alpha)$ (PML-RAR) and heterochromatin protein 1 [18].

E.histolytica is an interesting model in which to study DNA methylation because Ehmeth, an enzyme that belongs to the Dnmt2 family, is the unique DNA methyltransferase that is present in this parasite [12]. The presence of methylated cytosine in E. histolytica ribosomal DNA [12] and the scaffold/matrix attachment region [19], together with the evidence that mutations can result from accelerated deamination of methylated cytosines in the reverse transcriptase of LINE retrotransposon (RT LINE) [20] support a role for Dnmt2 in the control of repetitive elements. This role has been confirmed in lower eukaryote Dictyostelium discoideum [10,11] and in Drosophila [9]. Here, we establish that Ehmeth can catalyze the methylation of $\mathrm{tRNA}^{\mathrm{Asp}}$. Moreover, we report, for the first time, that enolase, in addition to its involvement in the glycolytic pathway $[21,22]$, is an inhibitor of Dnmt2.

\section{Results}

\section{Identification and validation of enolase as an interacting} partner of Ehmeth

We carried out a yeast two-hybrid screen using a bait vector that expressed pAS1-Ehmeth that was fused to the GAL4 binding domain (GAL4BD) and an E.histolytica cDNA library that was fused to the GAL4 activation domain (GAL4AD) as prey. For this purpose, $10^{6}$ clones were analyzed, and only two were selected based on their ability to grow on the selective medium (histidine, leucine, tryptophan and adenine) and results from the $\beta$ galactosidase complementation assays (data not shown). For each of the two positive clones, the recombinant plasmid that harbored the cDNA sequence that was fused to GAL4AD was isolated by transformation of $E$. coli cells, and then sequenced. These plasmids encode alcohol dehydrogenase (Accession number xp_653507.1) and enolase (Accession number xp_649161.1), respectively. Alcohol dehydrogenase was excluded from our analysis due to the presence of a frame shift mutation in its sequence.

In order to validate the interaction between enolase and Ehmeth, we carried out GST pull-down experiments. Ehmeth was first transcribed in vitro, and then translated in the presence of radioactive 35-S-methionine (TNT system) before incubating it with gluthatione beads that were coated with either GSTEhenolase or GST. The result of this pull-down experiment shows that Ehmeth binds specifically to GST-Ehenolase, and not to GST (Fig. 1).

The existence of sequence homology between members of the Dnmt2 protein family and members of the enolase family suggests that the interaction between Ehmeth and enolase is conserved outside the Entamoeba genus. In order to test this hypothesis, Drosophila and human Dnmt2 proteins were transcribed in vitro, translated, and then incubated with GST-Ehenolase. Interestingly, both Dnmt2 proteins were able to bind to enolase (Fig. 1).

\section{Localization of enolase in E.histolytica trophozoites}

We previously reported that enolase is secreted by activated trophozoites [23]. In order to get further insights into the cellular localization of this protein, cytoplasmatic and nuclear trophozoite proteins that were prepared from HM-1:MSS trophozoites were analyzed by western blotting with an antibody against enolase (Fig. 2A, 2C). The specificity of the enolase antibody that was raised against human enolase was confirmed against GSTEhenolase using GST alone as the negative control (data not shown). The efficiency of the protein fractionation was examined by western blot analysis using antibodies against EhMLBP, a nuclear protein [24] and myosin II, a cytoplasmatic protein [25], as controls. As expected, EhMLBP was detected in the nuclear fraction and Myosin II in the cytoplasmatic fraction of the parasite (Fig. 2A). Enolase was detected as a $47 \mathrm{kDa}$ protein present in the cytoplasmatic fraction of the parasite (Fig. 2A, 2C). Moreover, non-negligible amount of enolase were detected in the nuclear fraction of the parasite. To further validate these results, we

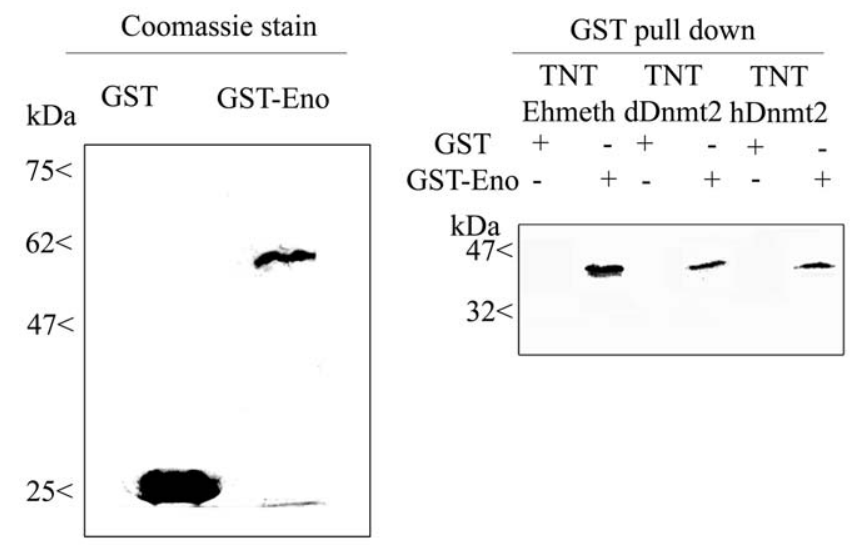

Figure 1. In vitro interaction between Ehmeth, dDnmt2, hDnmt2 and enolase. ${ }^{35} \mathrm{~S}$ labeled proteins Ehmeth (TNT-Ehmeth), dDnmt2 (TNT-dDnmt2) and hDnmt2 (TNT-hDnmt2) were incubated respectively with glutathione beads coated with GST or GST- Enolase and the interacting proteins were analyzed by SDS-Page as described in the Materials and Methods. Left panel: Coomassie staining of GST and GST-Enolase fusion protein used in the pull-down procedure. Right panel: Pull down products TNT-Ehmeth, TNT-dDnmt2 and TNT-hDnmt2 were detected by exposure of the membrane to an $\mathrm{x}$ ray film. doi:10.1371/journal.ppat.1000775.g001 
A.

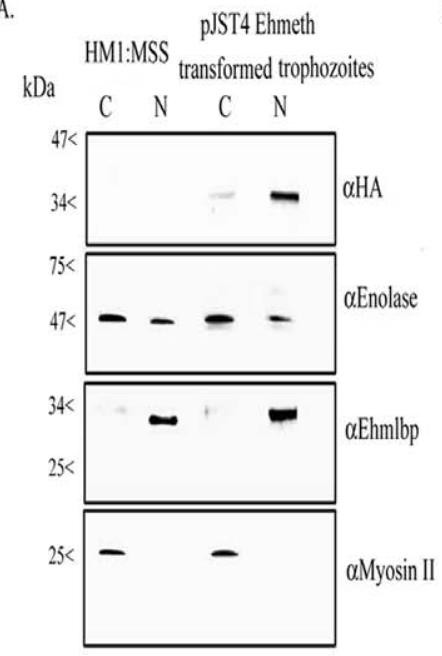

C.

$\mathrm{kDa}$
B.
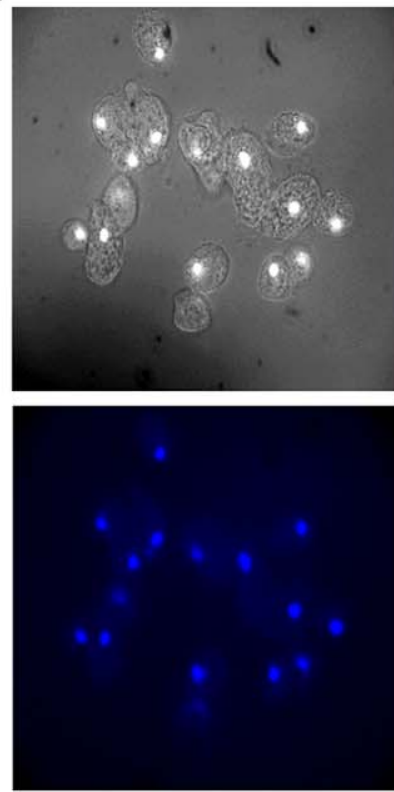

DAPI
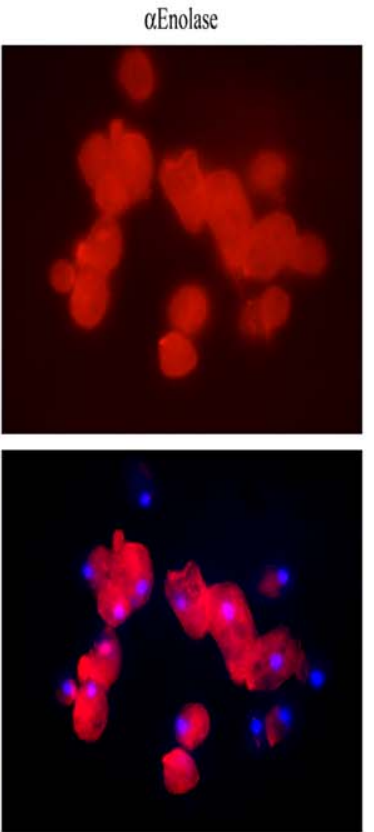

Overlay
Cytoplasmatic fraction

HMI:MSS NLS-Con NLS-Eno
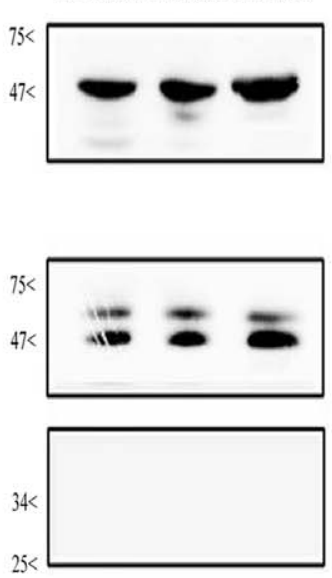

Nuclear fraction

HMI:MSS NLS-Con NLS-Eno
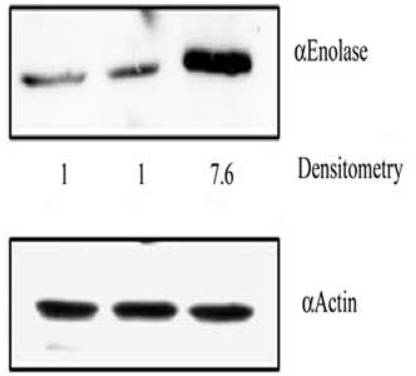

a.Actin

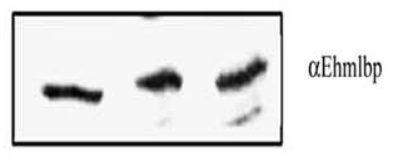

Figure 2. Enolase is present in the cytoplasmatic and nuclear fraction of E.histolytica. A. Cytoplasmatic (C) and nuclear (N) protein fractions of E.histolytica HM-1:MSS and pJST4-Ehmeth trophozoites were separated on 12\% SDS-PAGE and analyzed by western blot with an anti HA antibody, an anti enolase antibody, an anti EhMLBP antibody or an anti Myosin II antibody. B. Cellular localization of Ehenolase in E.histolytica trophozoites. Ehenolase was detected by immunofluorescence microscopy using anti-enolase antibody. Ehenolase distribution is shown in red using a primary anti-enolase antibody and a secondary antibody conjugated with Cy3. Nuclei (blue) were stained by DAPI. Computer-assisted image overlay analysis of the signal given by enolase antibody and by DAPI, shows that Ehenolase is ubiquitously present in trophozoites including in the nucleus. C. Cytoplasmatic and nuclear protein fractions of E.histolytica HM-1:MSS, trophozoites expressing a NLS-fused-scramble peptide (NLS-Con) (30) and trophozoites expressing a NLS-fused enolase (NLS-Eno) were separated on 12\% SDS-PAGE and analyzed by western blot with an anti enolase antibody, an anti actin antibody or an anti EhMLBP antibody. doi:10.1371/journal.ppat.1000775.g002

examined the localization of enolase in the parasite using immunofluorescent microscopy (Fig. 2B). The result of this analysis showed that enolase is ubiquitously present in the parasite including its nucleus.

\section{Ehmeth interacts with enolase in E.histolytica in vivo}

In order to test the binding of Ehmeth to enolase in the parasite, we conducted co-immunoprecipitation experiments using endog- enous enolase with a calmodulin, histidine, hemagglutin $(\mathrm{CHH})$ tagged-Ehmeth in pJST4-Ehmeth transfected trophozoites nuclear lysate. We chose a tagged Ehmeth rather than the endogenous Ehmeth in these co-immunoprecipitation experiments because the antibody that we previously raised against Ehmeth [12] was unable to immunoprecipitate the protein (data not shown). A hemagglutin (HA) antibody was used to detect $\mathrm{HA}$ in the $\mathrm{CHH}$ tag. The expression of CHH-tagged Ehmeth in the nuclear 
fraction of pJST4-Ehmeth transfected trophozoites was confirmed by western blot analysis using an HA antibody (Fig. 2A).

We observed that enolase co-immunoprecipitated with $\mathrm{CHH}-$ tagged-Ehmeth (Fig. 3 left panel, Control). Ehmeth also coimmunoprecipitated with enolase (data not shown). In order to exclude the possibility that enolase interacts with the CHH tag and not with Ehmeth, enolase was immunoprecipitated from a nuclear lysate of trophozoites that expressed a CHH-KLP5 tagged protein [26] using the HA antibody. We observed that enolase does not co-immunoprecipitate with the CHH-KLP5 tagged protein, and this result indicates that no interaction occurred between enolase and the $\mathrm{CHH}$ tag (Fig. 3, right panel).

\section{Mapping of Ehmeth binding site to enolase}

In order to delineate the enolase-interacting domains on Ehmeth, a series of deletion mutant proteins (Fig. 4, upper panel) were pulled down by either GST-Ehenolase or GST. We observed that N-terminal (from amino acid 1 to 103) and C-terminal (from amino acid 88 to 322) of Ehmeth were able to bind enolase in the same manner as full length Ehmeth (Fig. 4 lower panel). These results suggest that the specific region between amino acid 88 and 103, which is shared by the C-terminal and N-terminal Ehmeth mutant proteins is involved in the binding of Ehmeth to enolase. This region includes the catalytic site (domain IV) of Dnmt2 proteins [27]. In order to test this hypothesis, a mutant Ehmeth protein that lacks the amino acids 88 to 103 (Ehmeth $\Delta 88-103$ ) was generated, and its binding to GST-Ehenolase was examined. We found that the binding of Ehmeth $\Delta 88-103$ to enolase is impaired (Fig. 4 lower panel). It is important to emphasize that the input amount of the different Ehmeth deletion mutants proteins used in the GST-pull down assay were equivalent (data not shown). This result indicates that the domain IV contributes to the binding of Ehmeth to enolase. The catalytic domain of Dnmt2 proteins subsists as an exposed loop which is not part of the main structure [3]. According to this model, no significant conforma-

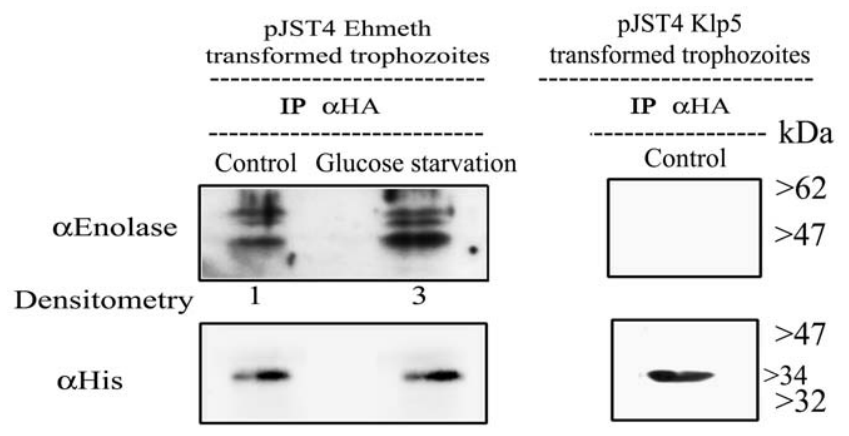

Figure 3. In vivo interaction of Ehmeth with enolase. Immunoprecipitation with an anti-HA antibody from a nuclear lysate of $E$. histolytica trophozoites that express Ehmeth as a $\mathrm{CHH}$-tagged protein (pJST4-Ehmeth) grown in regular media (control) and from trophozoites grown in a glucose starvation media (glucose starvation). Detection of immunoprecipitated proteins was done by western blot with an antienolase antibody. To validate that the same amounts of Ehmeth were used in the assay, immunoprecipated proteins were analyzed with an anti $\mathrm{His}$ antibody which detects the $\mathrm{CHH}$ tagged Ehmeth. As a negative control, immunoprecipitation with an anti-HA antibody from a nuclear lysate of E. histolytica trophozoites that express $\mathrm{CHH}-\mathrm{klp} 5$ was used (right panel). The physical interaction between enolase and Ehmeth is demonstrated only after immunoprecipitation from Ehmeth tagged trophozoites and this complex is enhanced following glucose starvation (3 fold according to Tina densitometry analysis).

doi:10.1371/journal.ppat.1000775.g003 tional change in the structure of Ehmeth is expected, following the deletion of the amino acids 88 to 103 .

\section{Enolase inhibits the binding of Ehmeth and hDnmt2 to EhMRS2 DNA}

We previously demonstrated that Ehmeth binds to EhMRS2, a DNA element, which contains the eukaryotic consensus scaffold/ matrix attachment regions (S/MAR) bipartite recognition sequences [19]. We hypothesized that enolase regulate Ehmeth activity because it binds to its catalytic site. In order to test this hypothesis, GST-Ehmeth was incubated with $\mathrm{P}^{32}$ labeled EhMRS2 DNA in presence of various amount of GST-Ehenolase, and the denaturant-resistant DNA-Ehmeth complex [3] was analyzed by SDS-PAGE under denaturing conditions. In agreement with a previous report [19], GST-Ehmeth forms a complex with EhMRS2 DNA which is characterized by a retarded band in the SDS gel (Fig. 5A). No complex was observed when the labeled EhMRS2 DNA probe was incubated with either GST or GST-Ehenolase (Fig. 5A). The presence of Ehmeth in the retarded band was confirmed by mass spectrometry analysis (Fig. S1). Remarkably, the formation of Ehmeth-EhMRS2 complex was inhibited in the presence of Ehenolase (Fig. 5A). In order to confirm this result for hDnmt2, we tested its ability to bind EhMRS2 DNA. We found that hDnmt2 binds to EhMRS2 DNA (Fig. 5A). The formation of hDnmt2-EhMRS2 DNA complex was also strongly inhibited by Ehenolase. These results suggest that an identical inhibitory mechanism is used by enolase to inhibit the binding of Ehmeth and hDnmt2 to EhMRS2 DNA.

\section{Enolase inhibits the tRNA ${ }^{\text {Asp }}$ methyltransferase activity of Ehmeth and hDnmt2}

It has been reported that $\mathrm{hDnmt} 2$ catalyzes the methylation of tRNA $^{\text {Asp }}[4,5,6]$. Therefore, we decided to examine this catalytic activity in E.histolytica because it has not yet been investigated in unicellular organisms. We found that the catalytic activity for Ehmeth was $9 \mathrm{U}$ (Fig. 5B, left panel). This activity is substantially lower (about 100-fold) than that of hDnmt2 (Fig. 5B, right panel). GST has no detectable tRNA ${ }^{\text {Asp }}$ MT activity. It has been reported that hDnmt2 methylates tRNA ${ }^{\text {Asp }}$ using a DNA methyltransferaselike catalytic mechanism [6]. This last observation predicts that enolase will also inhibit the $\mathrm{RNA}^{\mathrm{Asp}} \mathrm{MT}$ activity of Ehmeth and hDnmt2. We confirmed this prediction by showing that the activity of Ehmeth and hDnmt2 tRNA ${ }^{\text {Asp }}$ MT was strongly inhibited by enolase (approximately $60 \%$ and 90\% inhibition, respectively) (Fig. 5B).

\section{Effect of 2-phosphoglycerate (2-PG) on the inhibitory activity of enolase}

Enolase has been reported to undergo a conformational change following its binding to 2-PG [28,29]. This observation prompted us to examine the effect of 2-PG on the inhibitory activity of enolase. For this purpose, the ability of enolase to inhibit the methylation of RNA $^{\text {Asp }}$ by $\mathrm{hDnmt} 2$ was investigated in the presence of increasing concentrations of 2-PG. For this experiment, hDnmt2 was preferred to Ehmeth because its tRNA MT activity is significantly higher (see Fig. 5B). We observed that the inhibitory activity of enolase was reduced by 2-PG in a dosedependent manner (Fig. 6A). This result may be explained by reduced enolase binding to $\mathrm{hDnmt} 2$ when $2-\mathrm{PG}$ is present. In order to test this hypothesis, the binding of enolase and hDnmt2 was investigated in the presence of 2-PG $(7 \mathrm{mM})$. Following the addition of 2-PG, we observed that the binding of enolase to hDnmt2 was strongly reduced (Fig. 6B). These results indicate that 


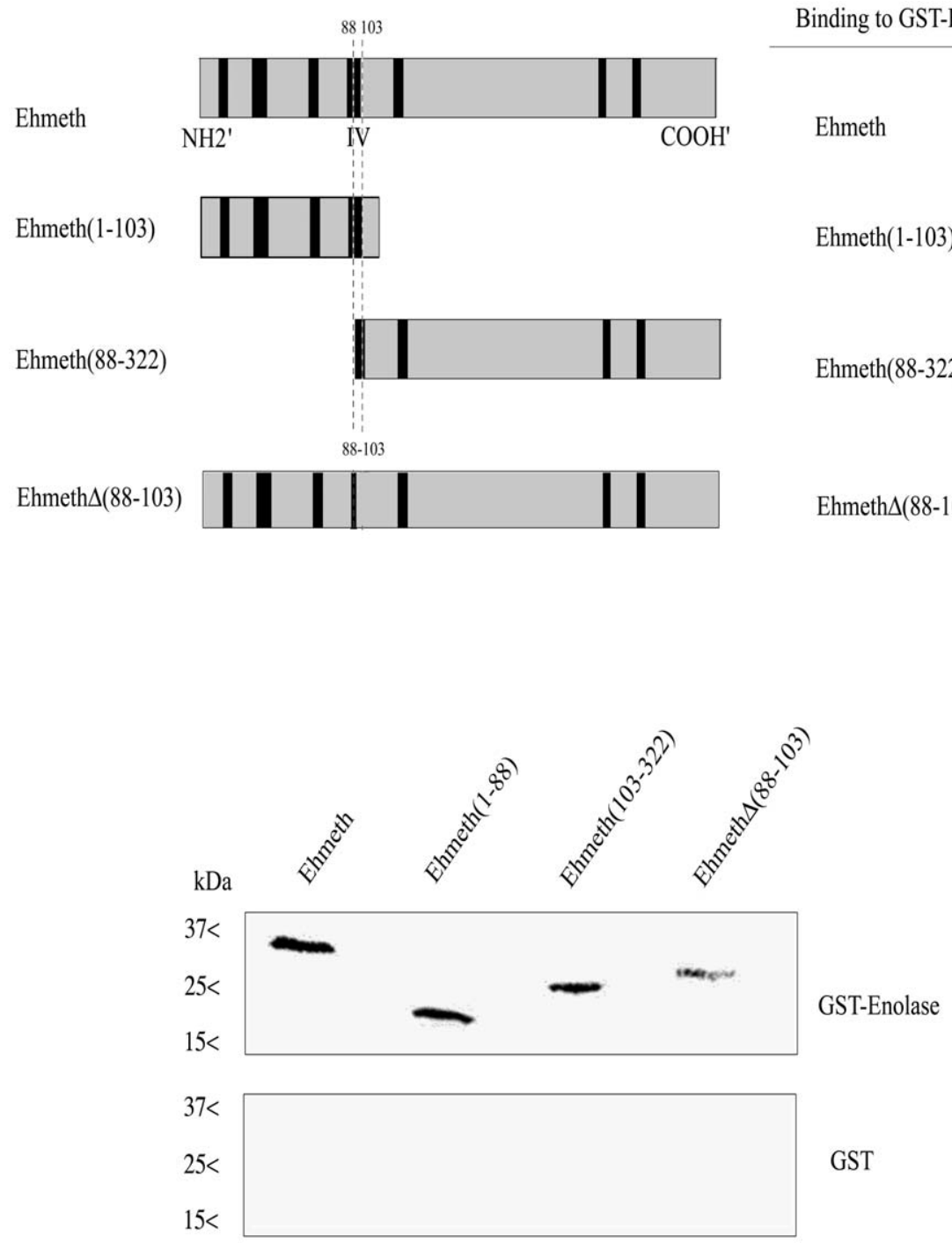

Figure 4. Mapping of the enolase binding region of Ehmeth. Upper panel: Scheme of the different Ehmeth mutants. Lower panel: Pull down experiment of different Ehmeth fragments with recombinant enolase. Whereas Ehmeth full length, Ehmeth (from amino acid 1 to103) and Ehmeth (from amino acid 88 to 322) where efficiently pull-down by enolase, Ehmeth that has its domain IV truncated interacts poorly with enolase. doi:10.1371/journal.ppat.1000775.g004

the inhibitory activity of enolase is regulated by its substrate, and suggest a link between the glycolytic pathway and Dnmt2 activity.

\section{Effect of glucose starvation on the localization of enolase, its binding to Ehmeth and on the DNA/tRNA asp methylation status}

Our previous results indicated that 2-PG modulates the inhibitory activity of enolase. In order to assess the physiological relevance of this observation, we used glucose starvation as a means to reduce the level of 2-PG in the parasite. We chose to quantify intracellular pyruvate, the end product of glycolysis, as the method to monitor the effect of 12-hour glucose starvation instead of a direct measurement of 2-PG because its determination is easier than 2-PG. We observed that the level of pyruvate in glucose-starved trophozoites for 12 hours was reduced by $50 \%$ when compared to non-starved control trophozoites $\left(8 \times 10^{-14} \mathrm{~mol} / \mathrm{ml}\right.$ vs $\left.8 \times 10^{-7} \mathrm{~mol} / \mathrm{ml}\right)$. Longer glucose starvation (24 hours) resulted in significant death of the parasite (more than $50 \%$ of the original population, data not shown).
The localization of enolase during glucose starvation was followed by western blot analysis of cytoplasmatic and nuclear lysates. We consistently observed that at least three times more enolase was present in the nuclear lysate of 12-hour glucosestarved trophozoites than in non-starved control trophozoites (Fig. 7A, right panel). No accumulation of enolase in the nucleus was observed in trophozoites exposed to heat shock or oxidative stress (data not shown). The addition of glucose to the starved parasite restored the original distribution of enolase. This result emphasizes that the mechanism used to accumulate enolase in the nucleus is reversible. Moreover, immunoprecipitation analysis of the enolase-Ehmeth complex following glucose starvation for 12 hours showed that more enolase-Ehmeth complex was formed in the starved trophozoites than in the non-starved control trophozoites (Fig. 3, left panel).

In this study we showed that enolase inhibits Ehmeth. Accordingly, we hypothesized that the formation of EnolaseEhmeth complex affects the level of DNA and tRNA ${ }^{\text {Asp }}$ methylation following glucose starvation of the parasite. In order to test this hypothesis, the level of tRNA and DNA methylation in 


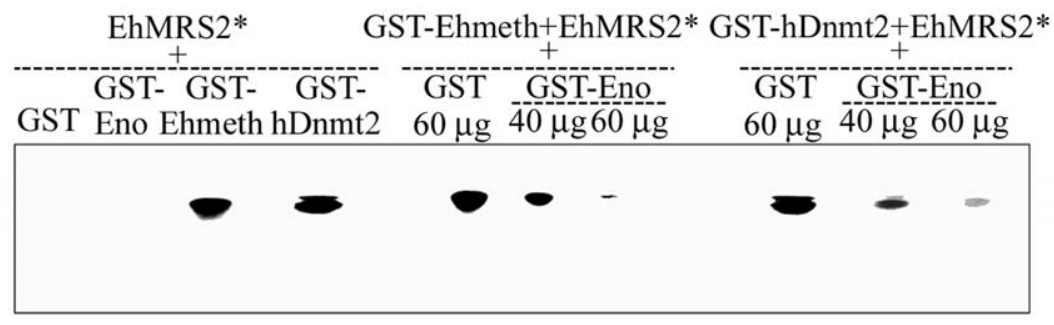

B
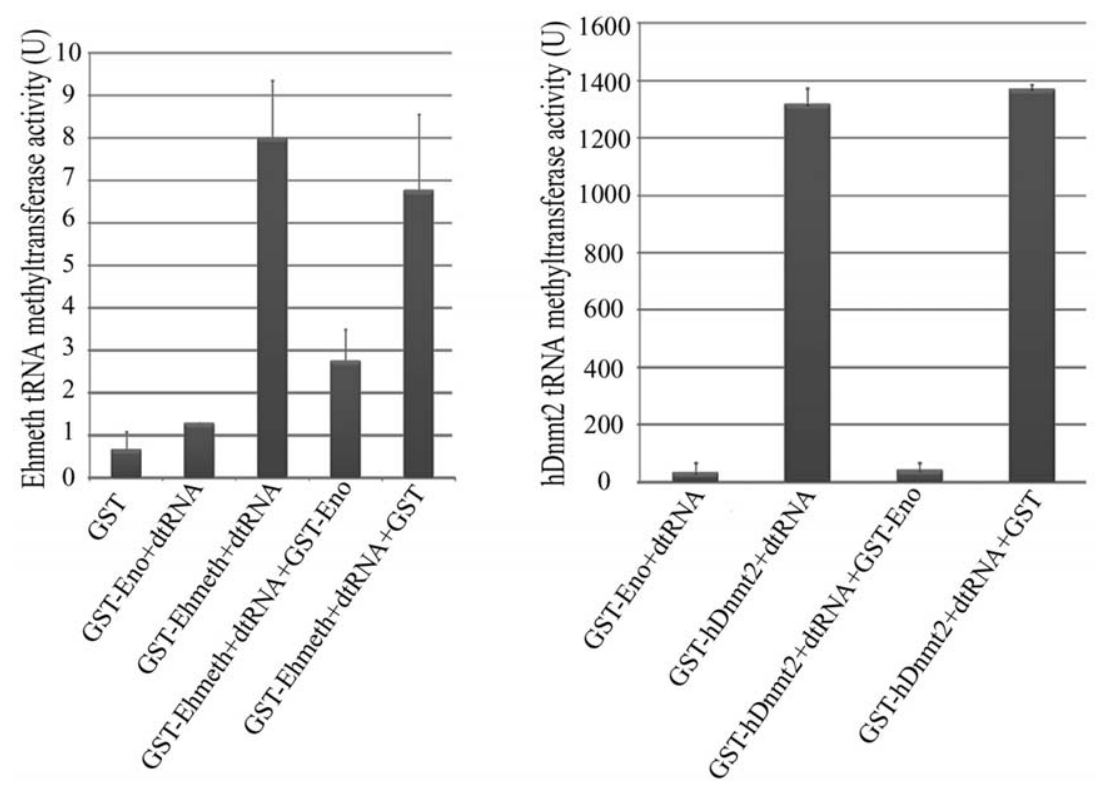

Figure 5. Enolase inhibits Ehmeth and hDnmt2 functions. A. The binding of $\gamma$-ATP labeled EhMRS2 DNA (EhMRS2* $-0.33 \mu \mathrm{g}$ ) to Ehmeth or hDnmt2 was detected as a DNA-protein complex. No complex was observed between GST and GST-Enolase incubated with EhMRS2 DNA. Enolase inhibits the binding of Ehmeth and hDnmt2 to EhMRS2 DNA in a dose dependent manner. B. Effect of enolase on the Ehmeth (left panel) and hDnmt2 (right panel) tRNA methyltransferase activity. The results represent the mean and standard deviation of three independent experiments $\left(\mathrm{P}_{\text {value }}<0.05\right)$. $\mathrm{U}=$ one unit corresponds to $1 \mathrm{pmol}$ of $\mathrm{H}^{3}$-Adomet incorporated/hour $/ \mathrm{nmol}$ of enzyme. doi:10.1371/journal.ppat.1000775.g005

control and glucose starved trophozoites was determined. Accordingly, we observed, a significant decrease in tRNA methylation $(38 \%)$ in glucose-starved trophozoites when compared to that determined in the non-starved trophozoites (Fig. 7B). Moreover, RT PCR analysis showed no significant difference in the amounts of tRNA ${ }^{\text {Asp }}$ in glucose- starved and non-starved control trophozoites (Fig. 7C). In contrast, when we examined the level of DNA methylation in genomic DNA of control and glucose-starved parasites with an m5C antibody using dot blot analysis we could not detect any differences (Fig. 7D) [12]. This result indicates that DNA methylation is not affected by glucose starvation probably due to the short time (12 hours starvation). Therefore, to further examine the effect of enolase accumulation in the nucleus on DNA methylation we expressed enolase constitutively followed by a Nuclear Localization Signal (NLS) in the parasite.

\section{Effect of enolase accumulation in the nucleus on DNA and tRNAasp methylation}

The transfected trophozoites with NLS Enolase and trophozoites expressing a random 12 amino acids peptide followed by a NLS [30] which were used as control (NLS-Con transfectants) were cultured continuously in the presence of $24 \mu \mathrm{g} \mathrm{mL}{ }^{-1} \mathrm{G} 418$ for one month. The localization of enolase in NLS-Eno and NLSCon transfectants was followed by western blot analysis of cytolasmic and nuclear lysates (Fig. 2C). We observed that 7 times more enolase was present in the nucleus of NLS-Eno transfectants than in NLS-con transfectants or non-transfected trophozoites (HM1:MSS) (Fig. 2C, right panel). The level of DNA and tRNA $^{\text {Asp }}$ methylation in NLS-Con and NLS-Eno was determined (Fig. 7B and D). A significant decrease in both DNA and tRNA ${ }^{\text {Asp }}$ methylation was observed in NLS-Eno transfectants when compared to that determined in NLS-Con transfectants. These results indicate that the continuous accumulation of enolase in the nucleus inhibit both Ehmeth DNA and tRNA ${ }^{\text {Asp }}$ MT activity.

\section{Discussion}

Of members of the Dnmt family of proteins, the roles of Dnmtl and Dnmt3 are relatively well understood. In contrast, our knowledge about Dnmt2 is scanty. Furthermore there is no information about the molecules which interact with this protein. Therefore, the identification of such molecules would be a key step 
A

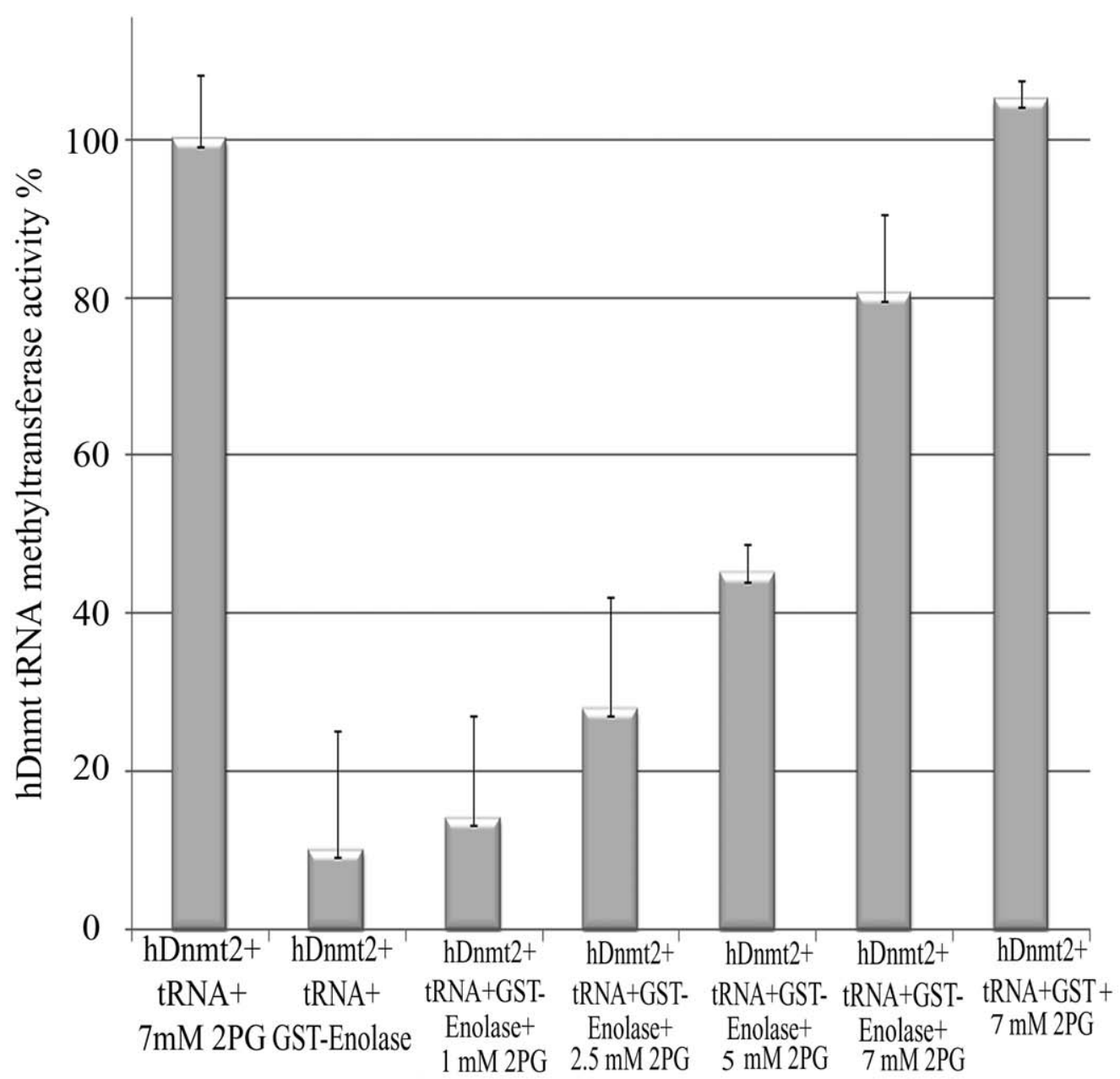

B

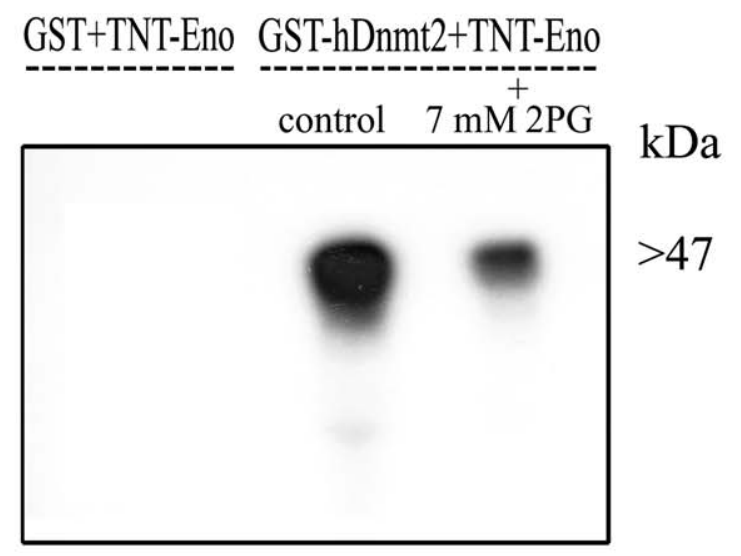

Figure 6. The influence of 2-PG on enolase inhibitory effect over Dnmt2 tRNA MT activity. A. Measure of the hDnmt2 tRNA methyltransferase activity in presence of enolase and increasing concentrations of 2 phosphoglycerate (2-PG). The activity of hDnmt2 measured in the presence of $7 \mathrm{mM} 2-\mathrm{PG}$ was regarded as $100 \%$. As already reported enolase strongly inhibits hDnmt2 in absence of 2-PG. The activity of hDnmt2 in presence of enolase is restored by 2-PG in a dose dependent manner. The results represent the mean and standard deviation of three independent experiments $\left(P_{\text {value }}<0.05\right)$. B. In vitro interaction between $\mathrm{hDnmt} 2$ and enolase in the presence of $7 \mathrm{mM} 2-\mathrm{PG} .{ }^{35} \mathrm{~S}$ labeled enolase (TNT-Eno) was incubated respectively with glutathione beads coated with GST or GST- hDnmt2 in presence or absence of 2-PG (7 mM). The pull down products was detected by exposure of the membrane to an $\mathrm{x}$ ray film. According to Tina densitometry analysis around 4 times less Enolase was pull down by hDnmt2 when 2-PG was present in the reaction.

doi:10.1371/journal.ppat.1000775.g006 
A.

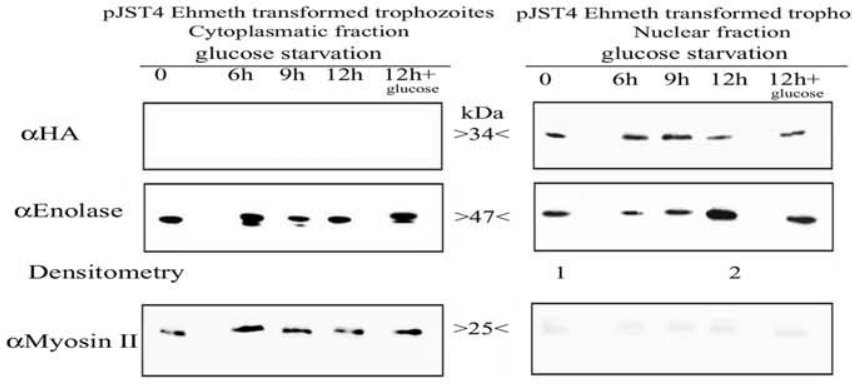

C.

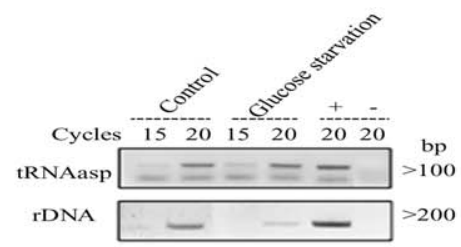

B.

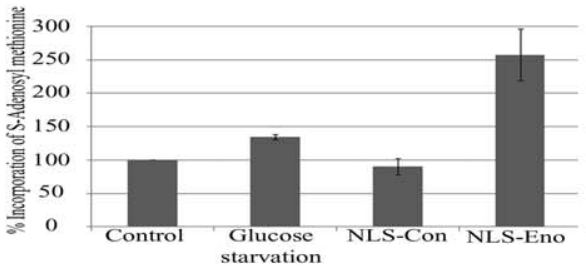

D.

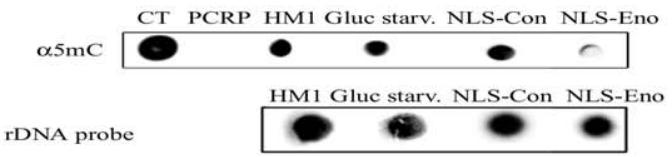

Figure 7. The effect of enolase accumulation in the nucleus over Dnmt2 tRNA and DNA MT activity. A. Western blot analysis of cytoplasmatic and nuclear protein fractions prepared from E.histolytica pJST4-Ehmeth trophozoites grown without glucose for $(0,6,9$ and 12 hours or for 12 hours of starvation followed by 12 hours of growth in presence of $1 \%$ glucose). Proteins were separated on $12 \%$ SDS-PAGE and analyzed by western blot with an anti HA antibody, an anti enolase antibody, or an anti Myosin II antibody. This figure is representative of at least three independent experiments. B. Effect of glucose starvation and continuous forced expression of enolase in the nucleus on the level of tRNA methylation in the parasite. RNA samples from trophozoites grown in regular (control), glucose starvation media (glucose starvation), NLS-Con trophozoites and NLS-Eno trophozoites were used as substrates for in vitro tRNA methylation assay performed with hDnmt2 (see materials and methods). The amount of methyl group incorporate in control RNA was taken as $100 \%$. The significant higher amount of methyl group incorporated in RNA prepared from glucose starved trophozoites ( $38 \%$ increases) and NLS-Eno trophozoites ( $250 \%$ increases) indicates the tRNA present in this sample were less methylated. The results represent the mean and standard deviation of three independent experiments $\left(P_{\text {value }}<0.05\right)$. C. RT PCR analysis of the tRNA ${ }^{\text {asp }}$ amount in trophozoites grown in regular (control) and glucose starvation media (glucose starvation). The amount of rDNA was used for the normalization of the data. D. Effect of glucose starvation and continuous forced expression of enolase in the nucleus on the level of $\mathrm{m} 5 \mathrm{C}$ methylation in the parasite. Genomic DNA was prepared from trophozoites grown in regular (control), glucose starvation media (glucose starvation), NLS-Con trophozoites and NLS-Eno trophozoites and dot blotted on nitrocellulose membrane in the indicated amounts. Genomic DNA from calf thymus (CT) or PCR product (PCRP) were used as positive and negative controls respectively. DNA methylation was detected with an antibody directed against 5-methylcytosine $(\alpha 5 \mathrm{mc})$ and the total amount of DNA was estimated by hybridization with a radioactive probe against rDNA. doi:10.1371/journal.ppat.1000775.g007

towards elucidating our understanding of Dnmt2 functions. Enolase, a glycolytic enzyme that catalyses the conversion of 2PG to phosphoenolpyruvate, (PEP) is to the best of our knowledge the first Dnmt2-interacting protein to be described. For many years, glycolytic enzymes have been considered to be housekeeping cytoplasmatic proteins. Based on the results of studies on the function(s) of the glyceraldehyde-3-phosphate dehydrogenase, this concept has changed, and it is now well accepted that some of these enzymes that includes enolase, are multifunctional proteins which are involved in gene transcription, DNA replication, DNA repair, and nuclear RNA export (for review see [31]). The inability to select in complex growth media mutants of Bacillus subtilis [32], Escherichia coli [32] and E.histolytica enolase (data not shown) supports this multifunctional role. The catalytic activity of enolase in E. histolytica has been characterized [22], and it was found to be co-secreted with serpin and aldehyde alcohol dehydrogenase by activated trophozoites [23]. Indeed, antibodies against enolase have been detected in patients with amebiasis, and this suggests that enolase plays a role in the virulence of the parasite [33]. Such a role has been already reported in bacteria where enolase binds plasminogen [34]. The results of this investigation show that enolase is present in the cytoplasm and nucleus of E.histolytica. This ubiquitous localization is not unique to E. histolytica. In mammals, there are three isoforms of enolase (for review [35]), and each is characterized by its tissue distribution and expression. In HeLa cells, A. thaliana, and Plasmodium yoelii, enolase was found also in the nucleus. These observations raise the question about the significance of enolase presence in the nucleus. The results of our investigations on the nuclear role of enolase suggest that it is a Dnmt2 inhibitor.

The results from several recent studies have fuelled the debate on whether Dnmt2 is a DNA methyltransferase, a tRNA methyltransferase, or both. The results of our investigation support the notion that E.histolytica Dnmt2 (Ehmeth) is a DNA methyltransferase and a tRNA methyltransferase. Indeed, this is the first report of Dnmt2 being a tRNA methyltransferase in lower eukaryotes. Enolase has been reported to bind the bacteriophagespecific DNA adenine methyltransferase M.EcoT1. Interestingly, enolase binding to M.EcoT1 did not influence M.EcoT1 catalytic activity [36]. The domain IV of Ehmeth includes the catalytic sites, and is widely conserved among DNA-(cytosine-C 5)-methyltransferase. The binding of enolase to the domain IV of Ehmeth is probably the main mechanism of its inhibitory action. Dnmt2 methylates tRNA using a DNA methyltransferase-like catalytic mechanism [6]. Therefore, it is not surprising that the binding of enolase to Ehmeth interferes with both EhMRS2 DNA recognition and $\mathrm{tRNA}^{\mathrm{Asp}} \mathrm{MT}$ activity. In $S$. cerevisiae, enolase interacts with cytosolic tRNA ${ }^{\text {Lys }}$ in order to enable its translocation into the mitochondria, thereby displaying a function as a tRNA chaperone [37]. Our data showed that enolase does not interact with either DNA or tRNA ${ }^{\text {Asp }}$, thereby excluding competition as a mechanism to explain its Dnmt2 inhibitory activity. Only a few proteins have been reported to interact with the G-terminal domain, which contains the catalytic site for Dnmts. The P23 protein is a protein 
that is associated with steroid receptor complexes binds to the Cterminal of Dnmtl [38]. However, its effect on Dnmtl activity is still unclear. In contrast, p53 has been shown to stimulate Dnmtl activity in vitro by binding to the G-terminal of Dnmtl [39]. This last example together with our findings reinforce the notion that catalytic activity of Dnmt protein can be modulated by proteins that interact with their C-terminal.

The accumulation of enolase in the nucleus and the formation of an additional Ehmeth-enolase complex following glucose starvation support a central role for glucose metabolism in the regulation of Ehmeth activity. Glucose starvation was preferred to drugs in order to inhibit glycolysis because (i) one of the unwanted action of such drugs is the inhibition of proteasome activity [40], and (ii) the physiological relevancy of glucose starvation during Entamoeba differentiation [41]. Metabolites can act as sensors of the cell energy status. Therefore, they are convenient regulators of enzymes under conditions of physiological stress such as glucose starvation. For example, glucose starvation affects the activation or silencing of rRNA expression [42].

Glucose starvation led to significant Trna ${ }^{\text {Asp }}$ demethylation, but not to DNA demethylation. In contrast, forced expression of enolase in the nucleus led to both DNA and tRNA ${ }^{\text {Asp }}$ demethylation. In mammals, active DNA demethylation is controversial [43]. Recently, a convincing mechanism of active DNA demethylation in which DNA glycosylase act as DNA demethylases through a base-excision-repair pathway has been proposed [44]. There is no evidence that active DNA demethylation occurs in E.histolytica. Passive demethylation occurs when DNA methylation is progressively reduced with cell division [45]. The generation time of the parasite is eight hours, and this would make it unlikely that DNA demethylation will occur following 12 hours of glucose starvation. However, this passive mechanism of DNA demethylation has probably occurred in the enolase-NLS strain during the numerous divisions of this strain. In contrast, the turnover of tRNA is much faster, and allows for rapid passive demethylation [46]. The physiological meaning of the Dnmt2-mediated methylation on tRNA ${ }^{\text {Asp }}$ is still unknown. tRNA methylation has been involved in the control of tRNA stability $[47,48]$. In $S$. cerevisiae, Trm9 mediated tRNA methylation is linked to the translation enhancement of genes related to stress response, DNA damage and other cellular functions [49,50]. Mitochondrial tRNA methylation mediated by Trm 5 was shown to regulate mitochondrial protein synthesis [51]. These different functions for tRNA methylation represent an interesting starting point for further research on the role of tRNA $^{\text {Asp }}$ methylation in E.histolytica.

To conclude, the results of this investigation provide in vivo and in vitro evidence that establishes enolase as the first Dnmt2 interacting protein. Moreover, our results also provide strong evidence that link glucose metabolism and Dnmt2 activity. In addition, we have also shown that Dnmt2 is a tRNA methyltransferase in lower eukaryotes. The question of the significance of enolase-Dnmt2 interaction is higher eukaryotes needs further investigation.

\section{Materials and Methods}

\section{Microorganisms used in this study}

Trophozoites of the E. histolytica strain HM-1:IMSS were grown under axenic conditions in Diamond's TYI-S-33 medium (glucose concentration $750 \mathrm{mg} / \mathrm{l}$ ) at $37^{\circ} \mathrm{C}$. Trophozoites in the log phase of growth were used in all experiments. For the glucose starvation assays, trophozoites in the exponential phase of growth were washed three times and transferred to Diamond's TYI-S-33 medium that has been prepared without glucose (glucose concentration $31 \mathrm{mg} / \mathrm{l})$. Recovery from glucose starvation was done by direct addition of $1 \%$ glucose to the culture of starved parasites.

Escherichia coli strain BL21 (DE3): $\mathrm{F}^{-}$ompT gal dcm lon $\operatorname{hsdS}_{\mathrm{B}}\left(\mathrm{r}_{\mathrm{B}}{ }^{-} \mathrm{m}_{\mathrm{B}}{ }^{-}\right) \lambda(\mathrm{DE} 3$ [lacI lacUV5-T7 gene 1 ind1 sam7 nin5])

Saccharomyces cerevisiae strain Y190: MATa, gal4 gall80 his3 trp1-901 ade2-101 ura3-52 leu2-3, - 112 + ura3::GAL $\rightarrow$ lacZ, LYS2: GAL(UAS) $\rightarrow$ HIS3 cyh $^{\text {r }}$

\section{DNA constructs used for:}

Yeast two-hybrid screen. An expression library of random primed c-DNA from E.histolytica was prepared by Vertis Biotechnologie AG (Germany), and cloned in the pACT2 vector downstream to the GAL4 activation domain.

Ehmeth was amplified by PCR from E. histolytica genomic DNA using the primers Ehmeth Bam and Ehmeth3' (Table 1), and then cloned in the pGEMT easy vector (Promega). The resultant vector was digested with BamHI and SalI, and the Ehmeth insert was then subcloned upstream to the GAL4 binding domain into the pASl plasmid that was previously linearized using BamHI and SalI (pGAL4-BD-Ehmeth).

In vitro translation. Ehmeth was amplified from E.histolytica genomic DNA by PCR using the primers Ehmeth start and Ehmeth3' (Table 1), and then cloned in pGEM- T-easy vector (pGEMT-Ehmeth). In order to serve as DNA template in the in vitro translation assay (TNT), Ehmeth was amplified from pGEMTEhmeth by PCR using the primers Ehmeth Kozak and Ehmeth 3' (Table 1).

Truncated Ehmeth 1-103 (from amino acid 1 to 103) was amplified from pGEMT-Ehmeth by PCR and the primers Ehmeth Kozak and Ehmeth 310 were used in order to serve as DNA template in the TNT system (Table 1). Truncated Ehmeth 88-322 (from amino acid 88 to 322) was amplified from pGEMTEhmeth by PCR using the primers Ehmeth 265 Kozak and Ehmeth $3^{\prime}$ (Table 1) in order to serve as DNA template in the TNT system.

The deletion of the 45 nucleotides that encoded Ehmeth amino acids 88-103 was done as follows: Ehmeth 1-88 was first amplified from pGEMT-Ehmeth by PGR using the primers Ehmeth start and Ehmeth $265 \mathrm{Bgl}$, and the PCR product was then cloned in pGEM-T-easy vector (pGEMT-Ehmeth1-88). Ehmeth 103-322 was amplified from pGEMT-Ehmeth by PCR using the primers Ehmeth 310 Bgl and Ehmeth 3', and the PCR product was cloned in pGEM- T-easy vector (pGEMT-Ehmeth103-322). The two plasmids, pGEMT-Ehmeth(88-322) and pGEMT-Ehmeth(1-88) were digested with Bgl II and EcoRI, and the Ehmeth DNA fragments were ligated using T4 DNA ligase (Biolabs). The product of the ligation was used as DNA template, and then amplified with the primers Ehmeth start and Ehmeth 3'. The resultant PCR product was cloned in a pGEM-T-easy vector (pGEMT-Ehmeth $\Delta(88-103))$. Ehmeth $\Delta(88-103)$ was amplified by PCR using the primers Ehmeth Kozak and Ehmeth3' in order to serve as DNA template for the TNT system.

The primers hDnmt2 $5^{\prime}$ and hDnmt2 $3^{\prime}$ were used for the amplification of hDnmt2 from a cDNA clone HGNC:2977 (Open Biosystems) and then cloned in a pGEEM- $\mathrm{T}$ easy vector (pGEMT-hDnmt2) following for use as template in TNT system hDnmt2 was amplified from pGEMT-hDnmt2 by PCR with primers TNT- hDnmt2 and hDnmt2 3'.

Expression of recombinant proteins in E.coli. For the expression of the recombinant GST fusion proteins, Ehenolase was amplified from genomic DNA by PCR using the primers GST-Enolase and Enolase Bgl II 3' (Table 1). The PCR product 
Table 1. Primers used in this study.

\begin{tabular}{|c|c|c|c|}
\hline Primer name & Sequence & Direction & Restriction site - underlined \\
\hline Ehmeth kozak & GGATCCTAATACGACTCACTATAGGGAGCCACCATGGAACAGAAACAAGT & Sense & BamHI \\
\hline Ehmeth 3' & TTATTCTTTTAAGTCATCGAATAAA & Antisense & \\
\hline GST Enolase & GGCGGATCCATGTCAATTCAAAAGGTTC & Sense & BamH I \\
\hline Enolase 3' & TATAGATCTTTAAGCAGTTGAATTTCTC & Antisense & Bgl II \\
\hline Ehmeth(305) & ТTAAATATTATAAATTTСTTTAAAAAC & Antisense & \\
\hline Eno dro sma & ATCCCGGGAATGACCATCAAAGCGATCAAGG & Sense & Sma I \\
\hline Eno dro & TTAAGCAGTTGAATTTCTCCAGTT & Antisense & \\
\hline Ehmeth 265 kozak & GGATCCTAATACGACTCACTATAGGGAGCCACCATGTCTAAACATAAAGA & Sense & BamHI \\
\hline Ehmeth 265 3' & ATAGATCTTATTGAATTATTATATGGTTGA & Antisense & Bgl II \\
\hline Ehmeth 310 3' & ТТАAАТАТТАТАAАТTТСТTТАAAAAC & Antisense & \\
\hline DNMT2 Kozak & GGATCCTAATACGACTCACTATAGGGAGCCACCATGGTATTTCGGGTCTT & sense & BamHI \\
\hline EhMRS2 5 & GATTTATTATATTATTAATGTTTGA & sense & \\
\hline EhMRS2 3 & GATCCCATACAAAAATAATTACA & antisense & \\
\hline Dnmt2 3' & ATAGCAAATATGTTGTATTTTGTTTTA & antisense & \\
\hline Dnmt2 5' & ATGGTATTTCGGGTCTTAGAACTATT & sense & \\
\hline Ehmeth Bam & TATGGATCCAACAGAAACAAGTAAATG & sense & BamH1 \\
\hline Enolase Bgl 3' & TATAGATCTTTAAGAGTTGAATTTCTC & antisense & Bgl II \\
\hline Ehmeth start & ATGCAACAGAAACAAGTAAATGTTAT & sense & \\
\hline Ehmeth kpn & TATGGTACCATGCAACAGAAACAAGTA & sense & Kpnl \\
\hline Ehmeth Bgl & TAGATCTCTTITAAGTCATCGAATA & antisense & Bgl II \\
\hline hDnmt2 Bam & GGCGGATCCATGGAGCCCCTGCGGGTGCT & Sense & \\
\hline hDnmt2 3' & TTATTCATATAAGATTTTGATTAGT & Antisense & \\
\hline hDnmt2 kozak & GGATCCTAATACGACTCACTATAGGGAGCCACCATGGAGCCACTGCGGGT & Sense & \\
\hline dtRNA & TGGCGCCCAACGTGGGGCTC & Antisense & \\
\hline $\mathrm{T7}$ & CGCGCGAAGCTTAATACGACTCACTATA & sense & \\
\hline TNT Eno & GGATCCTAATACGACTCACTATAGGGAGCCACCATGTCAATTCAAAAGGT & sense & \\
\hline Enolase kpn 5' & ATGGTACCATGTCAATTCAAAAGGTTC & sense & Kpnl \\
\hline Enolase NLS & GGATCCTTATCCAACCTTCTTTTCTITTTGGTCCAGATCTAGCAGTTGAATTTCTCCAGTTCTTCC & antisense & BamH1 \\
\hline
\end{tabular}

was then cloned in a pGEM-T easy vector (pGEM- Ehenolase), digested with BamHI and Not I, and then subcloned into the pGEX-4T1 vector (Amersham Pharmacia Biotech) that was previously linearized using BamHI and Not I. The preparation of Ehmeth-GST was done as previously described [12].

The primers hDnmt2-Bam and hDnmt2 3' (Table 1) were used for the amplification of hDnmt2 from pGEM-hDnmt2. The PCR product was then cloned in a pGEM-T easy vector, digested with BamHI and Not I, and then subcloned into the pGEX-4T1 vector that was previously linerarized with BamHl and Not I.

Expression of GHH tagged Ehmeth in E.histolytica. Ehmeth was amplified by PCR with the primers Ehmeth kpn and Ehmeth Bgl, and then cloned in the pJST4 expression vector (kindly provided by Prof. Lohia, Department of Biochemistry, Bose Institute, India) that was previously linearized with Kpn I and Bgl II. This vector allows the expression of a calmodulin binding domain, HA, His $(\mathrm{CHH})$-tagged protein in E. histolytica whose expression is driven by an actin promoter. The transfection of $E$. histolytica trophozoites was performed in the identical manner as previously described [52].

Expression of NLS enolase and NLS control in E.histolytica. Enolase was PCR amplified using primers Enolase kpn and Enolase NLS $3^{\prime}$ and cloned into the constitutive expression vector pEhNEO/CAT [53], which had been previously linearized by digestion with KpnI and BamHI. The pScramblePept 3 plasmid that was previously used to express a scramble peptide fused to a NLS sequence in E.histolytica [30] was used as control. The transfection of E. histolytica trophozoites was performed as described in [52].

\section{Two hybrid analysis}

S. cerevesiae Y190 was transformed with pGAL4-BD-Ehmeth $(500 \mu \mathrm{g})$ using the LiAc transformation method [54].

The pGAL4-BD-Ehmeth strain was transformed with E.histolytica cDNA library $(500 \mu \mathrm{g})$, and the transformants were then selected for their ability to grow on selective media that lacked leucine and tryptophan for four days at $30^{\circ} \mathrm{C}$. After this first round of selection, the resistant clones were plated on a more selective media that lacked leucine, tryptophan, histidine, and adenine, and then grown for five days at $30^{\circ} \mathrm{C}$. Fifteen resistant clones were then selected for further analysis. From these clones pACT2 vectors that contained cDNA inserts from E.histolytica library were isolated, and then transformed in the pGAL4-BD-Ehmeth strain. After the third round of selection, only two clones were able to grow on the selective media that lacked leucine, tryptophan, histidine, and adenine. 


\section{In vitro transcription/translation}

Coupled transcription and translation was carried out using a T7 TNT in vitro transcription/translation kit (Promega) in accordance with the manufacturer's instructions.

\section{Expression and purification of the recombinant proteins in E. coli BL21}

For the expression of the different GST-recombinant proteins, E. coli BL-21 that were transfected with the corresponding vectors were grown overnight in Luria Broth (LB) medium that contained $100 \mu \mathrm{g} / \mathrm{ml}$ ampicillin. The pre-cultures were inoculated (1:100) with 2xYT medium that was supplemented with $100 \mu \mathrm{g} / \mathrm{ml}$ ampicillin, and grown for about two hours at $37^{\circ} \mathrm{C}$ until the $\mathrm{OD}_{600}$ reached 0.8. Induction of the fusion protein was initiated by adding isopropyl-beta-D-thiogalactopyranoside (IPTG) at a final concentration of $0.5 \mathrm{mM}$ to the growing culture. After a fourhour incubation at $30^{\circ} \mathrm{C}$, the bacteria were harvested in lysis buffer $(100 \mathrm{mM} \mathrm{KCl}, 1 \mathrm{mM}$ DTT, $1 \mathrm{mM} \mathrm{PMSF}, 100 \mu \mathrm{g} / \mathrm{ml}$ Lysozyme and Leupeptine $100 \mu \mathrm{g} / \mathrm{ml}$ in PBS), and then sonicated for five minutes with 30 seconds of pulses with 30 seconds between each pulsation session. The lysis was completed by addition of BugBuster protein extraction reagent $(1: 100)$ (Novagen). The recombinant GST-proteins were purified under native conditions on a gluthatione-agarose resin (Sigma). Aliquots of GST fusion proteins that were bound to the glutathione-agarose beads were conserved at $-70^{\circ} \mathrm{C}$ for the pull-down assay. The remaining recombinant proteins were then eluted with glutathione elution buffer (Tris HCl $50 \mathrm{mM}$ pH 8.0, glutathione (Sigma) $10 \mathrm{mM}$ ), and their concentration was measured by Bradford's method [55].

\section{GST pull-down assay}

Gluthatione sepharose beads that were coated with GSTEnolase, or GST alone $(20-50 \mu \mathrm{g})$ were incubated with in vitro translated $\left[{ }^{35} \mathrm{~S}\right]$-methionine-labeled proteins $(15 \mu \mathrm{l}$ of the TNT reaction) in a final volume of $500 \mu \mathrm{l}$ pull-down buffer $(20 \mathrm{mM}$ Hepes pH 7.9, $100 \mathrm{mM} \mathrm{NaCl}, 1 \mathrm{mM}$ DTT, $6 \mathrm{mM} \mathrm{MgCl}_{2}, 20 \%$ glycerol, $1 \%$ Nonidet P40 and $0.5 \mathrm{mM}$ EDTA) for one hour at room temperature. The beads were then centrifuged at $3000 \mathrm{rpm}$ for five minutes, washed three times with the pull-down buffer, and then incubated at $100^{\circ} \mathrm{C}$ in presence of $25 \mu \mathrm{l} \mathrm{Laemmli} \mathrm{sample}$ buffer for five minutes. Interacting proteins were resolved on $12 \%$ SDS-polyacrylamide gel electrophoresis or 15\% SDS-polyacrylamide gel when TNT-Ehmeth (1-88) protein was used. The resultant bands were visualized after staining with Coomassie blue, drying and autography exposure.

\section{Trophozoites fractionation}

E.histolytica trophozoites nuclear and cytoplasmatic fractions were prepared in the identical manner as previously described [24]. Proteins were resolved on 12\% SDS-polyacrylamide gel electrophoresis, and then transferred to nitrocellulose membranes. Blots were then blocked ( $3 \%$ skim milk powder), and then reacted with either 1:500 enolase antibody (Santa Cruz Biotechnology) or with 1:500 HA antibody (Santa Cruz Biotechnology). After incubation with the first antibody, the blots were incubated with 1:5000 corresponding second antibody (Jackson ImmunoResearch), and then developed by enhanced chemoluminescence.

\section{Determination of pyruvic acid in the lysate of control and glucose-starved trophozoites}

Trophozoites $\left(10^{6}\right)$ that were grown in regular or glucosedeficient media were washed three times with PBS, and then resuspended in $2 \mathrm{ml}$ of PBS. The trophozoites were lysed by freezing and then thawing to produce a total protein lysate. The pyruvic acid level in trophozoite lysates was determined according to a previously described method [56]. Briefly, $1 \mathrm{ml}$ of 2,4dinitrophenylhydrazine (DNPH) $(0.0125 \%$ in $2 \mathrm{~N}$ HCL) was added to $1 \mathrm{ml}$ of trophozoite lysate. After 15 minutes of incubation at $37^{\circ} \mathrm{C}$ in a water bath, the sample was removed from the water bath, and $5 \mathrm{ml} 0.6 \mathrm{~N} \mathrm{NaOH}$ was added. The absorbance of the sample was then measured in a spectrophotometer at $420 \mathrm{~nm}$. A standard curve was generated using sodium pyruvate [56].

\section{Production of anti-enolase antibody}

Male BALB/c mice were injected intraperitoneally with $100 \mathrm{mg}$ of GST-Enolase recombinant protein that was emulsified in complete Freund's adjuvant. Two and four weeks later, the mice were injected with $100 \mathrm{mg}$ of the recombinant protein in incomplete Freund's adjuvant. One week after the 4-week injection, about $0.8 \mathrm{ml}$ of sera was obtained by retro-orbital puncture. Serum that was obtained from mice that were not injected with recombinant protein was used as the control.

\section{Microscopic localization of enolase in trophozoites}

Trophozoites in a logarithmic growth phase were harvested, transferred to $8 \mathrm{~mm}$ round wells on glass slides, and then incubated for $30 \mathrm{~min}$ at $37^{\circ} \mathrm{C}$ in order to allow them attach to the glass surface. An indirect immunofluorescence assay was performed. For this purpose, the amebae were fixed with cold methanol for $20 \mathrm{~min}$ at $-20 \mathrm{C}$, and then incubated with 1:400 enolase antibody for one hour at room temperature. After washing, the samples were then incubated with goat Cy3conjugated anti-mouse (Jackson ImmunoResearch) 1:1000 for one hour. Samples were then stained with 4,6-diamidino-2phenylindole dihydrochloride (DAPI,Sigma) in order to visualize the nuclei. Fluorescent images were captured by a CCD camera attached to an Axioscop2 (Zeiss) epifluorescence microscope with a 100/1.30 Plan Neofluar oil immersion objective and a differential interference contrast filter. The images were analyzed with ImagePro@Plus software (Media Cyberneticx, USA).

\section{Immunoprecipitation assays}

Aliquots of nuclear protein fraction $(50 \mu \mathrm{g})$ were diluted in $20 \mathrm{mM}$ Hepes pH 7.5, $150 \mathrm{mM} \mathrm{NaCl}, 0.1 \%$ Triton, 10\% glycerol (HNTG buffer) $(300 \mu \mathrm{l})$, and then incubated with protein $\mathrm{G}$ beads (Sigma) $(10 \mu \mathrm{l})$ for 30 minutes at $4^{\circ} \mathrm{C}$. Non-specific interacting proteins were excluded by centrifugation $\left(3000 \mathrm{rpm}\right.$ at $4^{\circ} \mathrm{C}$ for 5 minutes). The supernatant was incubated with either 1:200-HA antibody or enolase antibody) for two hours at $4^{\circ} \mathrm{C}$. Following incubation protein $\mathrm{G}-$ Sepharose beads $(20 \mu \mathrm{l})$ were added to the samples which were then incubated for 16 hours at $4^{\circ} \mathrm{C}$. Immunoprecipitated proteins were collected by centrifugation, washed three times with HNTG buffer, and then resolved by $12 \%$ SDS-polyacrylamide gel electrophoresis. The proteins were then transferred to nitrocellulose membranes by western blot analysis, and detected with the relevant antibody, mouse anti-enolase or rabbit anti-HA.

\section{Preparation of the EhMRS probe}

EhMRS2 was amplified from E.histolytica genomic DNA by PCR and the primers EhMRS2 5 and EhMRS2 3. EhMRS2 DNA (10 pmol) was end-labeled with T4-polynucleotide kinase (New England Biolabs) and $\gamma$-ATP in accordance with the manufacturer's recommendations. Unincorporated $\gamma$-ATP was removed with the ProbeQuant kit (Amersham). 
Examination of the effect of enolase on the binding of Ehmeth and hDnmt2 to EhMRS2 DNA

Gluthatione sepharose beads that were coated with GSTEhmeth, GST-hDnmt2, or GST alone $(35 \mu \mathrm{g})$ were incubated in $100 \mu \mathrm{l}$ blocking buffer (3\% BSA and salmon sperm DNA $1 \mu \mathrm{g} / \mathrm{ml}$ in standard binding buffer $(20 \mathrm{mM}$ Tris- $\mathrm{HCl} \mathrm{pH} 8,50 \mathrm{mM} \mathrm{NaCl}$, $1 \mathrm{mM}$ EDTA in double distilled water) for 30 minutes at room temperature. Following blocking the beads were washed three times with standard binding buffer, and incubated with either $40 \mu \mathrm{g}$ or $60 \mu \mathrm{g}$ of GST- Enolase for one hour at room temperature $(100 \mu \mathrm{l}$ final reaction volume). The probe $(0.3 \mu \mathrm{g})$ was then added, and binding was carried out at $4{ }^{\circ} \mathrm{C}$ overnight. Subsequently, the beads were washed three times in standard binding buffer, boiled with $25 \mu \mathrm{l}$ Laemmli sample buffer for 5 minutes; proteins were separated on $10 \%$ SDS-polyacrylamide gel electrophoresis. The signal of the proteins that were bound to the labeled DNA probe was detected directly from the polyacrylamide gel on X-ray film (Fuji).

\section{tRNA preparation}

The methylation assay of $\mathrm{tRNA}^{\text {Asp }}$ with the DNMT2 variants was performed using a previously described method [6]. Briefly, the DNA template that encoded Drosophila tRNA ${ }^{\text {Asp }}$ was amplified by PCR and the T7 primer and tRNA ${ }^{\text {Asp }}$ primer. For in vitro transcription, $100 \mu \mathrm{l}$ of the PCR reaction were incubated with $200 \mu \mathrm{l} 2 \times$ transcription buffer $(80 \mathrm{mM}$ Tris-HCl at $\mathrm{pH} 8.1$, $2 \mathrm{mM}$ Spermidine, $10 \mathrm{mM}$ DTT, 0.02\% Triton-X-100, $60 \mathrm{mM}$ $\mathrm{MgCl} 2,4 \mu \mathrm{g} / \mathrm{ml} \mathrm{BSA}$ ), $5 \mathrm{mM}$ of each NTP (final concentration), and $10 \mu \mathrm{l}$ of T7-Polymerase (200 units/ $\mu \mathrm{l}$; Fermentas) in a final volume of $400 \mu \mathrm{l}$ for three hours at $37^{\circ} \mathrm{C}$. Transcripts were purified over $12 \%$ denaturing PAGE, and bands of correct size were excised, eluted in $0.5 \mathrm{M}$ ammonium acetate, and precipitated with two volumes of $100 \%$ ethanol. After centrifugation, RNA pellets were washed once with $80 \%$ ethanol, and then dissolved in double distilled water. The concentration of tRNA was measured with a nanodrop spectrophotometer.

\section{Matrix-assisted laser-desorption/ionization - time of flight (MALDI-TOF) mass spectrometry analysis}

Protein bands of interest were excised from the SDS-polyacrylamide gel and digested with trypsin using a previously published protocol [57], and then analyzed by MALDI-TOF mass spectrometry analysis that was done at the Institute of Biology, Technion, Israel. The peptide mass profiles that were produced by MALDITOF mass spectrometry were processed using PepMiner (this software is described at http://www.haifa.il.ibm.com/projects/ verification/bioinformatics/). Peptides masses were compared with the theoretical masses that were derived from the sequences that were in the SWISS-PROT/TrEMBL (http://www.expasy.ch/ sprot/), the NCBI (http://www.ncbi.nlm.nih.gov/), and the $E$. histolytica genome project databases (http://pathema.jcvi.org/cgibin/Entamoeba/GenomePage.cgi?org = eha2).

\section{References}

1. Spada F, Rothbauer U, Zolghadr K, Schermelleh L, Leonhardt H (2006) Regulation of DNA methyltransferase 1. Adv Enzyme Regul 46: 224-234.

2. Jeltsch A (2006) Molecular enzymology of mammalian DNA methyltransferases. Curr Top Microbiol Immunol 301: 203-225.

3. Dong A, Yoder JA, Zhang X, Zhou L, Bestor TH, et al. (2001) Structure of human DNMT2, an enigmatic DNA methyltransferase homolog that displays denaturant-resistant binding to DNA. Nucleic Acids Res 29: 439448.

\section{In vitro tRNA methylation assay}

Aliquots (40 pmol) of Drosophila tRNA ${ }^{\text {Asp }}$ were incubated with $0.4 \mathrm{nmol}$ Ehmeth or $0.04 \mathrm{nmol}$ GST-hDnmt2 for three hours at $37^{\circ} \mathrm{C}$ in $40 \mu \mathrm{l}$ of methylation buffer $(100 \mathrm{mM}$ Tris $/ \mathrm{HCl}$ at $\mathrm{pH} 7.5,5 \%$ glycerol, $5 \mathrm{mM} \mathrm{MgCl} 2,1 \mathrm{mM}$ DTT, and $100 \mathrm{mM}$ $\mathrm{NaCl}$ ) that contained $4.2 \mu \mathrm{M}$ labeled [methyl-3H] AdoMet (NEN). When we examined the effect of enolase on Ehmeth activity, GST-Enolase $(2 \mathrm{nmol})$ or GST as negative control $(2 \mathrm{nmol})$ were incubated with Ehmeth for one hour at $37^{\circ} \mathrm{C}$. When we examined the effect of enolase on hDnmt2 activity, GST-Enolase $(0.4 \mathrm{nmol})$ or GST $(0.4 \mathrm{nmol})$ were incubated respectively with hDnmt 2 for one hour at $37^{\circ} \mathrm{C}$. Samples $(8 \mu \mathrm{l})$ were taken from reaction mix $(40 \mu \mathrm{l})$ at different times, and loaded on Whatman filters. The filters were then washed with $10 \%$ Trichloroacetic Acid Solution (TCA) three times and finally with $100 \%$ ethanol. After washing the filters were air-dried and transferred into tubes following addition of $3 \mathrm{ml}$ scintillation liquid (CytoScint). The incorporated radioactivity was measured in a scintillation counter (Counter Beta Tri-Carb 2100TR). tRNA methyltransferase activity (one unit $(\mathrm{U})$ ) was expressed as the incorporation of 1 pmol AdoMet per hour per nmol of protein. In vitro tRNA methylation assay in the presence of 2 phosphoglycerate (2-PG) (Fluka) was done in the identical manner with minor modifications. Increasing 2-PG concentrations (1-7 mM) were incubated with GST-Enolase $(0.4 \mathrm{nmol})$ and with hDnmt2 $(0.04 \mathrm{nmol})$. The activity of hDnmt2 in the presence of $7 \mathrm{mM} \mathrm{2-}$ PG was used as control.

\section{In vitro methylation assay of total RNA}

Total RNA was prepared with the TRI-Reagent kit (Sigma) from control or glucose-starved trophozoites and treated with DNase I to remove any contamination of DNA. Aliquots from the treated RNA $(20 \mu \mathrm{g})$, were used as substrates for hDnmt2 in vitro tRNA methylation assay (see above protocol). The amount of methyl groups that was incorporated by hDnmt2 into the tRNA of each sample is proportional to the amount of unmethylated tRNA in the control sample.

\section{Accession numbers of genes and proteins mentioned in the text}

E.histolytica enolase: XP_649161.1, Ehmlbp: XP_649236, Ehmeth: XP_655267.2, Myosin II: XM_651936.1, hDNMT2: NP_004403.1

\section{Supporting Information}

Figure S1 Mass spectrometry analysis of the retarded band observed following incubation of Ehmeth with EhMRS2 DNA. Found at: doi:10.1371/journal.ppat.1000775.s001 (0.49 MB TIF)

\section{Author Contributions}

Conceived and designed the experiments: AT SA. Performed the experiments: AT RST SA. Analyzed the data: AT MH SA. Contributed reagents/materials/analysis tools: RG MH. Wrote the paper: AT SA.
4. Goll MG, Kirpekar F, Magoert KA, Yoder JA, Hsieh CL, et al. (2006) Methylation of tRNAAsp by the DNA methyltransferase homolog Dnmt2. Science 311: 395-398.

5. Hengesbach M, Meusburger M, Lyko F, Helm M Use of DNAzymes for sitespecific analysis of ribonucleotide modifications. RNA 14(1): 180-187.

6. Jurkowski T, Meusburger M, Phalke S, Helm M, Nellen W, et al. (2008) Human DNMT2 methylates tRNA(Asp) molecules using a DNA methyltransferase-like catalytic mechanism. RNA 14(8): 1663-1670. 
7. Okano M, Xie S, Li E (1998) Dnmt2 is not required for de novo and maintenance methylation of viral DNA in embryonic stem cells. Nucleic Acids Res 26: 2536-2540.

8. Kunert N, Marhold J, Stanke J, Stach D, Lyko F (2003) A Dnmt2-like protein mediates DNA methylation in Drosophila. Development 130: 5083-5090.

9. Phalke S, Nickel O, Walluscheck D, Hortig F, Onorati MC, et al. (2009) Retrotransposon silencing and telomere integrity in somatic cells of Drosophila depends on the cytosine-5 methyltransferase DNMT2. Nat Genet 41: 696-702.

10. Katoh M, Curk T, Xu O, Zupan B, Kuspa A, et al. (2006) Developmentally regulated DNA methylation in Dictyostelium discoideum. Eukaryot Cell 5: $18-25$.

11. Kuhlmann M, Borisova BE, Kaller M, Larsson P, Stach D, et al. (2005) Silencing of retrotransposons in Dictyostelium by DNA methylation and RNAi. Nucleic Acids Res 33: 6405-6417.

12. Fisher O, Siman-Tov R, Ankri S (2004) Characterization of cytosine methylated regions and 5-cytosine DNA methyltransferase (Ehmeth) in the protozoan parasite Entamoeba histolytica. Nucleic Acids Res 32: 287-297.

13. Jeltsch A, Nellen W, Lyko F (2006) Two substrates are better than one: dual specificities for Dnmt2 methyltransferases. Trends Biochem Sci 31: 306-308.

14. Mund C, Musch T, Strodicke M, Assmann B, Li E, et al. (2004) Comparative analysis of DNA methylation patterns in transgenic Drosophila overexpressing mouse DNA methyltransferases. Biochem J 378: 763-768.

15. Pinarbasi E, Elliott J, Hornby DP (1996) Activation of a yeast pseudo DNA methyltransferase by deletion of a single amino acid. J Mol Biol 257: 804-813.

16. Rountree MR, Bachman KE, Baylin SB (2000) DNMT1 binds HDAC2 and a new co-repressor, DMAP1, to form a complex at replication foci. Nat Genet 25: 269-277.

17. Fuks F, Burgers WA, Godin N, Kasai M, Kouzarides T (2001) Dnmt3a binds deacetylases and is recruited by a sequence-specific repressor to silence transcription. Embo J 20: 2536-2544.

18. Turek-Plewa J, Jagodzinski PP The role of mammalian DNA methyltransferases in the regulation of gene expression. Cell Mol Biol Lett 10(4): 631-647.

19. Banerjee S, Fisher O, Lohia A, Ankri S (2005) Entamoeba histolytica DNA methyltransferase (Ehmeth) is a nuclear matrix protein that binds EhMRS2, a DNA that includes a scaffold/matrix attachment region (S/MAR). Mol Biochem Parasitol 139: 91-97.

20. Harony H, Bernes S, Siman-Tov R, Ankri S (2006) DNA methylation and targeting of LINE retrotransposons in Entamoeba histolytica and Entamoeba invadens. Mol Biochem Parasitol 147: 55-63.

21. Holt A, Wold F (1961) The isolation and characterization of rabbit muscle enolase. J Biol Chem 236: 3227-3231.

22. Saavedra E, Encalada R, Pineda E, Jasso-Chavez R, Moreno-Sanchez R (2005) Glycolysis in Entamoeba histolytica. Biochemical characterization of recombinant glycolytic enzymes and flux control analysis. FEBS J 272: 1767-1783.

23. Riahi Y, Siman-Tov R, Ankri S (2004) Molecular cloning, expression and characterization of a serine proteinase inhibitor gene from Entamoeba histolytica. Mol Biochem Parasitol 133: 153-162.

24. Lavi T, Isakov E, Harony H, Fisher O, Siman-Tov R, et al. (2006) Sensing DNA methylation in the protozoan parasite Entamoeba histolytica. Mol Microbiol 62: 1373-1386.

25. Arhets $\mathrm{P}$, Gounon $\mathrm{P}$, Sansonetti $\mathrm{P}, \mathrm{N}$ aG (1995) Myosin II is involved in capping and uroid formation in the human pathogen Entamoeba histolytica. Infection and Immunity 63: 4358-4367.

26. Dastidar PG, Majumder S, A L (2007) Eh Klp5 is a divergent member of the kinesin 5 family that regulates genome content and microtubular assembly in Entamoeba histolytica. Cell Microbiol 9: 316-328.

27. Hermann A, Schmitt S, Jeltsch A (2003) The human Dnmt2 has residual DNA(cytosine-C5) methyltransferase activity. J Biol Chem 278: 31717-31721.

28. Boël G, Pichereau V, Mijakovic I, Mazé A, Poncet S, et al. (2004) Is 2phosphoglycerate-dependent automodification of bacterial enolases implicated in their export. Journal of molecular biology 2: 485-496.

29. Gerlt JA, Babbitt PC, Rayment I (2005) Divergent evolution in the enolase superfamily: the interplay of mechanism and specificity. Arch Biochem Biophys 433: 59-70.

30. Lavi T, Siman-Tov R, Ankri S (2008) EhMLBP is an essential constituent of the Entamoeba histolytica epigenetic machinery and a potential drug target. Molecular Microbiol 69: 55-66.

31. Kim J, Dang C (2005) Multifaceted roles of glycolytic enzymes. Trends Biochem Sci 30: 142-150
32. Commichau FM, Rothe FM, Herzberg C, Wagner E, Hellwig D, et al. (2009) Novel activities of glycolytic enzymes in Bacillus subtilis: interactions with essential proteins involved in mRNA processing. Mol Cell Proteomics 8: 1350-1360.

33. Carrero JC, Petrossian P, Acosta E, Sanchez-Zerpa M, Ortiz-Ortiz L, et al. (2000) Cloning and characterization of Entamoeba histolytica antigens recognized by human secretory IgA antibodies. Parasitol Res 86: 330-334.

34. Pancholi V, Fischetti VA (1998) alpha-enolase, a novel strong plasmin(ogen) binding protein on the surface of pathogenic streptococci. J Biol Chem 273: $14503-14515$.

35. Pancholi V (2001) Multifunctional alpha-enolase: its role in diseases. Cell Mol Life Sci 58: 902-920.

36. Gassner C, Schneider-Scherzer E, Lottspeich F, Schweiger M, Schweiger M, et al. (1998) Escherichia coli bacteriophage T1 DNA methyltransferase appears to interact with Escherichia coli enolase. Biol Chem 379: 621-623.

37. Entelis N, Brandina I, Kamenski P, Krasheninnikov I, Martin R, et al. (2006) A glycolytic enzyme, enolase, is recruited as a cofactor of tRNA targeting toward mitochondria in Saccharomyces cerevisiae. Genes and Development 5: 1609-1620.

38. Zhang X, Verdine GL (1996) Mammalian DNA cytosine-5 methyltransferase interacts with p23 protein. FEBS Lett 392: 179-183.

39. Esteve P, Chin H, Pradhan S (2005) Human maintenance DNA (cytosine-5)methyltransferase and p53 modulate expression of p53-repressed promoters. Proc Natl Acad Sci U SA 102: 1000-1005.

40. Kang Ht Fau - Hwang ES, Hwang ES (2006) 2-Deoxyglucose: an anticancer and antiviral therapeutic, but not any more a low glucose mimetic.

41. Thepsuparungsikul V, Seng L, Bailey GB (1971) Differentiation of Entamoeba: encystation of E. invadens in monoxenic and axenic cultures. J Parasitol 57: 1288-1292.

42. Grummt I, Ladurner AG (2008) A metabolic throttle regulates the epigenetic state of rDNA. Cell 133: 577-580.

43. Ooi SK, Bestor TH (2008) The colorful history of active DNA demethylation. Cell 133: 1145-1148.

44. Gehring M, Reik W, Henikoff S (2009) DNA demethylation by DNA repair. Trends Genet 25: 82-90.

45. Morgan HD, Santos F, Green K, Dean W, Reik W (2005) Epigenetic reprogramming in mammals. Hum Mol Genet 14 Spec No 1: R47-58.

46. Schlegel R, Iversen P, Rechsteiner M (1978) The turnover of tRNAs microinjected into animal cells. Nucleic Acids Res. pp 3715-3729.

47. MjJ, Bystrom AS (2002) Dual function of the tRNA(m(5)U54)methyltransferase in tRNA maturation. RNA 8: 324-335.

48. Studte P, Zink S, Jablonowski D, Bar C, von der Haar T, et al. (2008) tRNA and protein methylase complexes mediate zymocin toxicity in yeast. Mol Microbiol 69: $1266-1277$.

49. Begley U, Dyavaiah M, Patil A, Rooney JP, DiRenzo D, et al. (2007) Trm9catalyzed tRNA modifications link translation to the DNA damage response. Mol Cell 28: 860-870.

50. Jablonowski D, Zink S, Mehlgarten C, Daum G, Schaffrath R (2006) tRNAGlu wobble uridine methylation by Trm9 identifies Elongator's key role for zymocininduced cell death in yeast. Mol Microbiol 59: 677-688.

51. Lee C, Kramer G, Graham DE, Appling DR (2007) Yeast mitochondrial initiator tRNA is methylated at guanosine 37 by the Trm5-encoded tRNA (guanine-N1-)-methyltransferase. J Biol Chem 282: 27744-27753.

52. Fisher O, Siman-Tov R, Ankri S (2006) Pleiotropic phenotype in Entamoeba histolytica overexpressing DNA methyltransferase (Ehmeth). Mol Biochem Parasitol 147: 48-54

53. Hamann L, Nickel R, Tannich E (1995) Transfection and continuous expression of heterologous genes in the protozoan parasite Entamoeba histolytica. Proc Natl Acad Sci U SA 92: 8975-8979.

54. Gietz R, Schiestl R (2007) High-efficiency yeast transformation using the LiAc/ SS carrier DNA/PEG method. Nat Protoc 2: 31-34.

55. Bradford MM (1976) A rapid and sensitive method for the quantitation of microgram quantities of protein utilizing the principle of protein-dye binding. Anal Biochem 72: 248-254.

56. Anthon GE, Barrett DM (2003) Modified method for the determination of pyruvic acid with dinitrophenylhydrazine in the assessment of onion pungency. Journal of the Science of Food and Agriculture 83: 1210-1213.

57. Shevchenko A, Wilm M, Vorm O, Mann M (1996) Mass spectrometric sequencing of proteins silver-stained polyacrylamide gels. Anal Chem 68: $850-858$. 